\title{
Self-Lubricating Composites Enriched in the Surface with Molybdenum and Nickel
}

\author{
Keli Vanessa Salvador Damin ${ }^{a, b *}$, Alícia Correa Lucena ${ }^{a}$,Tatiana Bendo ${ }^{a}$, Aloísio Nelmo Klein $^{a}$, \\ Cristiano Binder ${ }^{a}$ \\ ${ }^{a}$ Universidade Federal de Santa Catarina, Departamento de Engenharia Mecânica, \\ Florianópolis, SC, Brasil \\ ${ }^{b}$ Instituto Federal de Educação Ciência e Tecnologia de Santa Catarina, Departamento de Mecânica, \\ Chapecó, SC, Brasil
}

Received: January 11, 2019; Revised: July 16, 2019; Accepted: December 5, 2019

\begin{abstract}
In powder metallurgy the addition of alloying elements is a widely used alternative to increase the service life of mechanical components. However, they have an associated cost. One less exploited process is surface enrichment (or surface alloying), whose same result is obtained on the surface, but at a much lower cost. Self-lubricating composites are especially complex to be enriched, precisely because they have to avoid the deposition of alloying elements over the lubricant stocks. This paper reports the characterization and tribological properties of self-lubricating composites enriched with molybdenum or nickel. Sintered samples were produced for comparative purposes. Wear resistance, friction coefficient and wear rate were analyzed for the evaluation of tribological properties. The results showed that the enrichment process did not cover the lubricant stocks. In addition, the Mo-enriched samples presented the best tribological results, with a $250 \%$ increase in scuffing resistance in relation the sintered sample, and lower wear rate.
\end{abstract}

Keywords: Self-lubricating composites, surface enrichment, surface alloying, wear rate, scuffing resistance.

\section{Introduction}

A way of improving mechanical properties of a selflubricating component produced by powder metallurgy (PM) is by adding alloying elements, which increase the properties of the matrix and at the same time maintain the self-lubricating properties of the component ${ }^{1}$. The presence of the alloying elements increase the mechanical strength of the matrix due to the microstructural modification, such as the formation of different phases or precipitates ${ }^{2,3}$.

However, this performance improvement has a high cost since the addition of alloying elements occurs throughout the component while, in most engineering applications, an increase strength is necessary only in the volume near the surface. This occurs because in the mechanical components the wear of a few micrometers is enough for them to lose their function and dimensional tolerance and to be discarded to avoid the failure of the mechanical system in which they are installed $\mathrm{d}^{4,5}$.

Plasma surface enrichment is an attractive process to increase the mechanical and tribological properties of self-lubricating components. In this process the addition of alloying elements occurs only in the region where it is needed, that is, on the surface and just below it ${ }^{6}$. In addition, as the process is carried out simultaneously the sintering step $7,8,9$, there is not the increase in processing time and still cost reduction relative to the raw material used.

Recently, some authors ${ }^{10,11,12,13}$ evaluated the tribological properties of plasma surface alloyed materials. The results

*e-mail: kelivsd@gmail.com showed that the surface alloying process generally reduces the coefficient of friction (COF) and the wear rate of the materials. However, studies about the enrichment of selflubricating components are still a gap. This is because enrich the surface of a self-lubricating composite without cover the lubricant stocks is a challenge, since the enrichment process occurs over the entire surface. Considering this, our research group has investigated the enrichment of selflubricating composites avoiding cover the lubricant stocks on the surface ${ }^{14}$.

In this investigation, the enrichment of a self-lubricating composite with molybdenum and nickel was carried out. The modifications obtained by the enrichment and the tribological and mechanical properties of the obtained self-lubricating composite are shown and discussed.

\section{Materials and Methods}

In this paper, samples of self-lubricating composites were submitted to the plasma surface enrichment process with molybdenum or nickel. The composite samples were produced by powder injection molding (PIM) using an Arburg Allrounder model 320s. Sintered iron-based composites were produced by mixing carbonyl iron powder CL-OM $\left(\mathrm{d}_{50}\right.$ of $3.9-5.2$ $\mu \mathrm{m}$ and $0.6 \mathrm{wt} . \%$ carbon) and silicon carbide ( $\mathrm{SiC}$ ) powder with a particle size of $15 \mu \mathrm{m}$. The $\mathrm{SiC}$ powder was used as precursor to produce the graphite nodules (solid lubricant) due the dissociation of $\mathrm{SiC}$ previously described in ${ }^{15}, 16,17$. This dissociation starts at $1050{ }^{\circ} \mathrm{C}$ and becomes more intense 
at the sintering temperature $\left(1150^{\circ} \mathrm{C}\right){ }^{17}$. Therefore, in these samples a large part of the solid lubricant is generated during the sintering stage. The samples were produced with a chemical composition of $\mathrm{Fe}+0.6 \mathrm{C}+3 \mathrm{SiC}$.

For injection, the feedstock was prepared in a Winkworth mixer $\left(180{ }^{\circ} \mathrm{C}, 70 \mathrm{rev} \mathrm{min}^{-1}, 90 \mathrm{~min}\right)$ using $8 \mathrm{wt} . \%$ of an organic binder system containing polypropylene, paraffin wax, ethylene vinyl acetate copolymer (EVA), stearic acid (surfactant) and amide wax. After the extraction of the binders, described in ${ }^{18}$, theses specimens were sintered and enriched (with Mo or Ni) simultaneously in a hybrid plasma reactor described in other works ${ }^{7,19,20}$. The parameters used in the plasma treatments and samples nomenclature are presented in Table 1. Reference samples, just sintered (S1 sample) was also produced for comparatives purposes.

The samples were plasma sintered and enriched onto the grounded electrode (confined anode-cathode configuration). Three holders with different compositions were designed and assembled for placing the samples in the reactor. To perform the Mo-enrichment, a holder was made of TZM alloy (approximately 99.4 wt.\% Mo) and to perform the Ni-enrichment, a holder was made of Ni200 alloy (approximately 99.7 wt.\% Ni). In order to set up basis for comparison, an additional set of samples (S1) was sintered on an AISI 1020 steel holder.

After plasma treatments, the top and cross section of the samples were analyzed by scanning electron microscopy (SEM) (TESCAN Vega 3), energy dispersive X-ray (EDX) (Oxford x-act) and by microhardness measurements. The microhardness measurements were performed using a Vickers indenter with a $0.01 \mathrm{~kg}$ load for 15 seconds in a Future-Tech FM-800 microdurometer. The microhardness tests were performed according to MPIF Standard 51 and $52^{21,22}$.

To determine which phases were present after plasma treatments, X-ray diffraction (XRD) was performed using a Philips X'Pert diffractometer. The diffractograms were recorded from the specimen surfaces to identify the phases from the positions of the diffraction peaks, data from the JCPDS were used

The tribological characterization was evaluated using two experimental routes with a CETR UMT tribometer. First using reciprocating sliding tests with regular increments of $7 \mathrm{~N}$ each 10 minutes described in ${ }^{23}$ to determine the scuffing resistance. In this paper, the scuffing resistance was defined as the work (N.m) until the COF exceeds the value of 0.2 and stays above this limit for at least 190 seconds ${ }^{17}$, this is important to avoid a premature interruption of the test due fluctuations in COF that may occur during increments of normal load. The second route was also carried out with reciprocating sliding tests, but using a constant normal load of $7 \mathrm{~N}$ for 1 hour to obtain the friction coefficient and wear rate of the samples and counter-bodies. For all experimental routes the counter-body was hard AISI 52100 steel ball with $5 \mathrm{~mm}$ diameter, the oscillation frequency was $2 \mathrm{~Hz}$ and the wear track length was $10 \mathrm{~mm}$. The tests were replicated at least 3 times for each experimental route.

White light interferometry (ZygoNewView 7300) was used to quantify the specimen wear volumes. Topographical data processing was performed using the MountainsMap Universal $7.1^{\circledR}$ software. The wear volume $(\Delta \mathrm{V})$ of the counter-body was estimated using equations 1,2 , and 3 for the spherical cap volume, as illustrated in Figure 1.

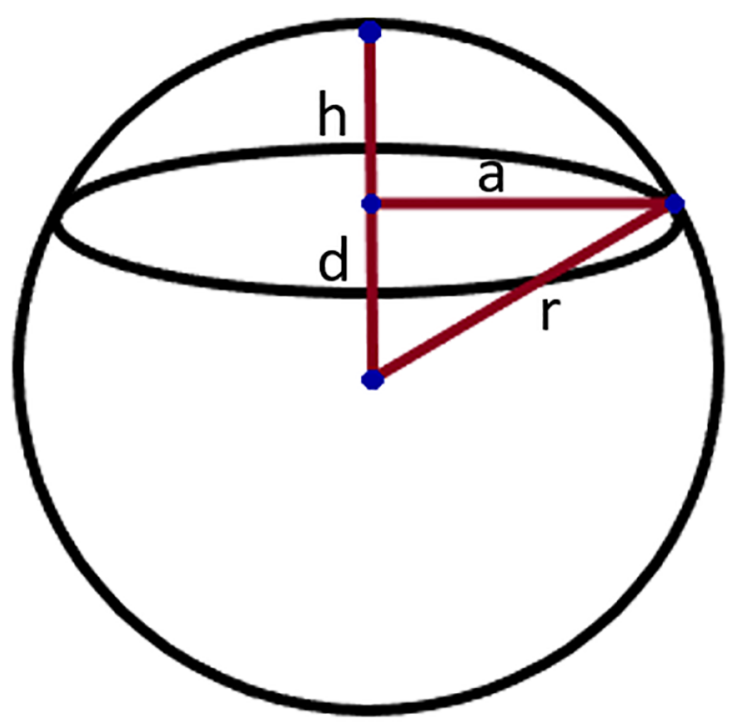

Figure 1. Scheme for quantifying wear volumes of counter-bodies.

The value of "a" was obtained using optical microscopy of the wear scar.

$$
\begin{gathered}
d=\sqrt{\left(r^{2}-a^{2}\right)} \\
h=(r-d) \\
\Delta V=\frac{\pi h}{6}\left(3 a^{2}+h^{2}\right)
\end{gathered}
$$

Table 1. Parameters of plasma treatments.

\begin{tabular}{lcccccccc}
\hline Nomenclature & Process & $\begin{array}{c}\text { Temperature } \\
\left({ }^{\circ} \mathbf{C}\right)\end{array}$ & $\begin{array}{c}\text { Time } \\
(\mathbf{m i n})\end{array}$ & $\begin{array}{c}\text { ton - pulse } \\
\text { active time } \\
(\boldsymbol{\mu s})\end{array}$ & $\begin{array}{c}\text { Pressure } \\
(\mathbf{P a})\end{array}$ & $\begin{array}{c}\text { Delta V } \\
(\mathbf{V})\end{array}$ & $\begin{array}{c}\text { Gas } \\
\text { Mixture } \\
(\mathbf{\%})\end{array}$ & $\begin{array}{c}\text { Flow } \\
\left(\mathbf{m}^{3} / \mathbf{s}\right)\end{array}$ \\
\hline S1 & Sintering & 1150 & 60 & 20 & $1,33 \times 10^{2}$ & 400 & $5 \mathrm{H}_{2} / 95 \mathrm{Ar}$ & $4 \times 10^{-6}$ \\
Mo2 & Mo enriched & 1150 & 60 & 150 & $2,66 \times 10^{2}$ & 500 & $20 \mathrm{H}_{2} / 80 \mathrm{Ar}$ & $4 \times 10^{-6}$ \\
Ni2.5 & Ni enriched & 1150 & 60 & 150 & $3,32 \times 10^{2}$ & 600 & $20 \mathrm{H}_{2} / 80 \mathrm{Ar}$ & $4 \times 10^{-6}$ \\
\hline
\end{tabular}


Where " $\Delta V$ " is the wear volume, " $r$ " is the radius of the sphere; "a" is the radius of the cap base. " $h$ " is the height of the cap, and " $d$ " is the difference between the radius of the sphere and the radius of the cap base.

\section{Results and Discussions}

Considering that for a self-lubricating component to maintain the lubricating properties, it is necessary that the solid lubricant is also available on the surface after the plasma enrichment process. To evaluate the surface microstructure of the samples after the enrichment processes, SEM and EDX investigation was performed. The results are shown in Figure 2. It is possible observe three different regions for the Mo2 sample (as indicated in Figure 2(a)), which have different Mo concentrations. The region 1 is representative of the lubricant stocks. The enrichment with nickel was homogeneous, reaching up to $11.2 \mathrm{wt} \% \%$ on the Ni2.5 sample (Figure 2(b)). In this sample, some lubricant stocks regions was enriched reaching up to $2.2 \mathrm{wt} . \%$ of nickel. This behavior was not observed for the Mo2 sample. It is assumed that the non-significant coverage of the solid lubricant by nickel or molybdenum is due to the process of generation of lubricant reservoirs used in this work. In this process, the solid lubricant reservoirs (stocks) are generated in situ during the sintering by dissociation of $\mathrm{SiC}$ precursor ${ }^{15,16}$. The graphite nodules were produced at the same time to the enrichment processes, which is performed simultaneously with the sintering. This allowed the formation of new graphite nodules during all enrichment, which resulted in a non-significant coverage of the lubricant stocks at the end of the process. For comparative purposes, sample $\mathrm{S} 1$ shows the surface of a specimen without enrichment (Figure 2(c)). No significant differences were observed in the morphology of the solid lubricant between the samples.

The X-ray diffractograms recorded from the surface of samples are shown in Figure 3. The diffractogram of the S1 sample presented the ferrite and graphite phases. For the Mo2
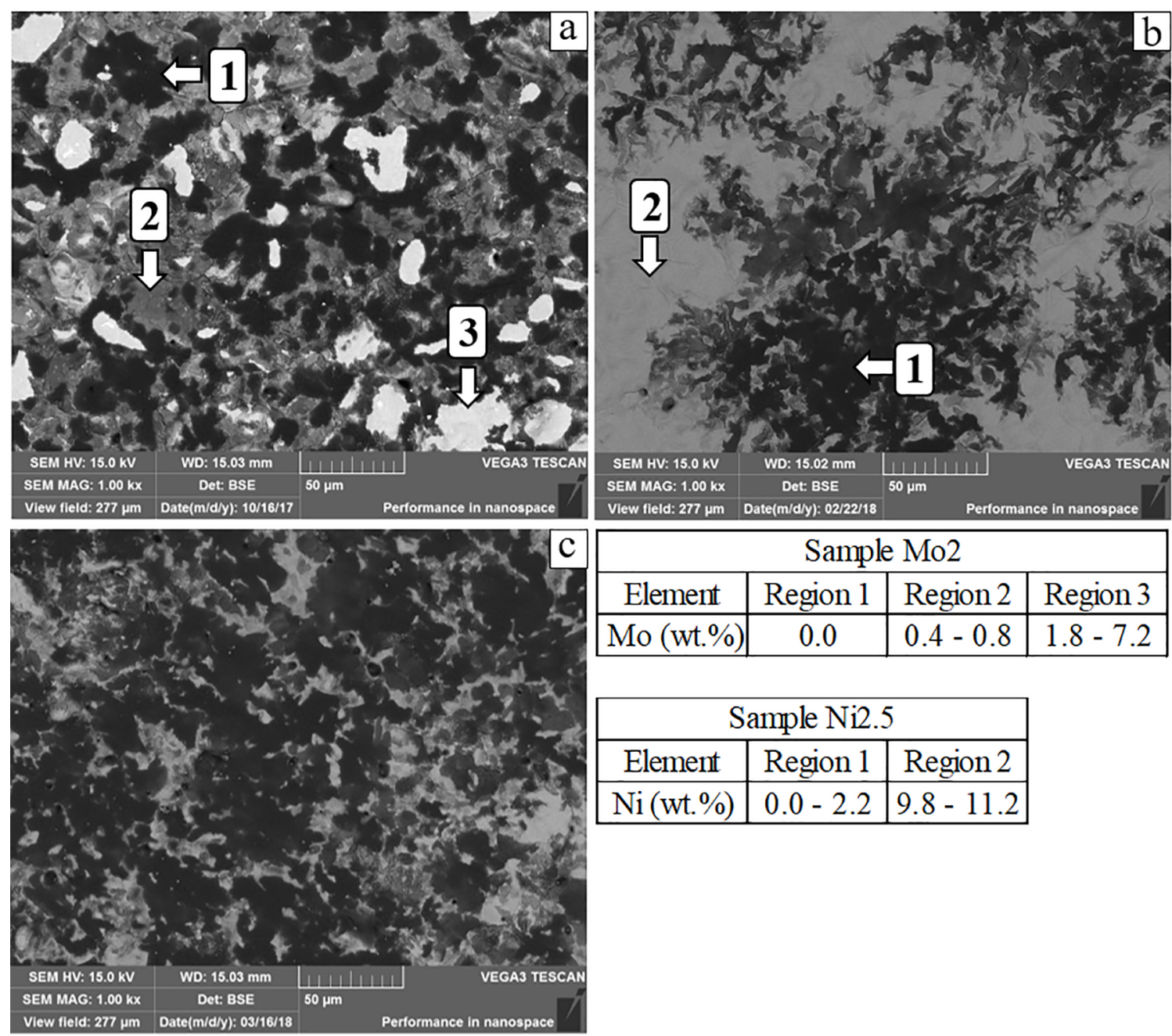

\begin{tabular}{|c|c|c|c|}
\hline \multicolumn{4}{|c|}{ Sample Mo2 } \\
\hline Element & Region 1 & Region 2 & Region 3 \\
\hline Mo (wt.\%) & 0.0 & $0.4-0.8$ & $1.8-7.2$ \\
\hline
\end{tabular}

\begin{tabular}{|c|c|c|}
\hline \multicolumn{3}{|c|}{ Sample Ni2.5 } \\
\hline Element & Region 1 & Region 2 \\
\hline Ni (wt.\%) & $0.0-2.2$ & $9.8-11.2$ \\
\hline
\end{tabular}

Figure 2. SEM image of surface of the samples and EDX results: (a) in sample Mo2 there was no coating of lubricant stocks with molybdenum, (b) a partial coating of lubricant stocks was observed in sample Ni2.5, enriched with nickel and (c) sample S1, sintered only. 
sample, the martensite phase was also present. The presence of martensite is justified by the high concentration of molybdenum in some regions, (until 7.8 wt. \% showed at Figure 2(a)) which increased the hardenability of these material ${ }^{24,25,26}$.

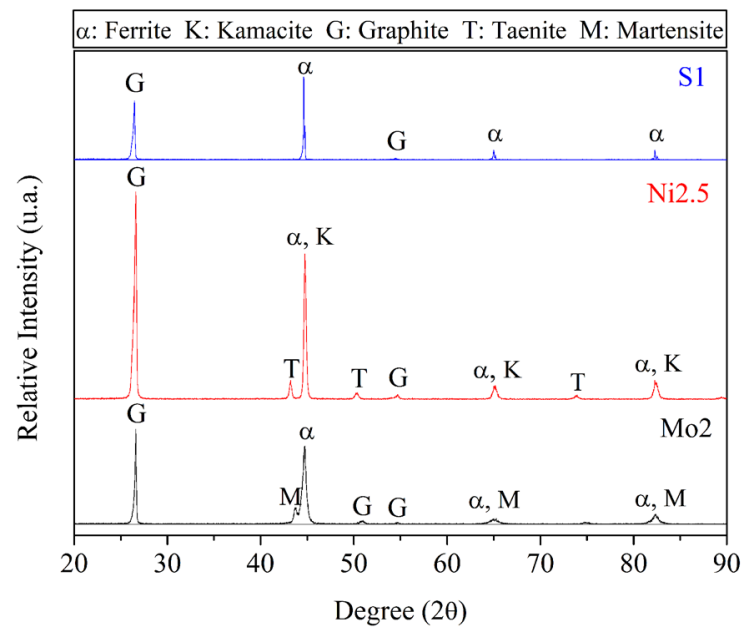

Figure 3. X-ray diffraction patterns for the samples. The numbers of JCPDS cards used to identify the phases were: 01-075-1621 (graphite), 01-087-072 ( $\alpha$-Fe) 00-0440-1293 (martensite) 00-0370474 (kamacite) and 00-047-1417 (taenite).

The diffractogram of the Ni-enriched sample indicated ferrite, graphite, kamacite and taenite phases. The kamacite is a solid solution of nickel-poor iron, with CCC structure and microhardness around $181 \mathrm{HV}^{27,28}$. On the other hand, the taenite is a solid solution of nickel-rich iron, with CFC structure, and microhardness depending on the nickel content, ranging from $350-500 \mathrm{HV}^{27,28,29,30}$.
Images obtained by SEM of the cross-sectioned samples are presented in Figure 4. The micrograph of sintered sample (Figure 4(a)) corroborates the results obtained by XRD, where the graphite peak corresponds to the graphite nodules generated during the dissociation of $\mathrm{SiC}^{15,16}$. Ferrite and perlite were also observed, which is in accordance with the microhardness profile obtained for this sample shown in Figure 5.

In the micrograph of Mo2 sample it is possible to observe the Mo-enriched layer (region between the arrows) (Figure 4(b)). This layer has a thickness of $15.82 \pm 4.02 \mu \mathrm{m}$ and an almost constant molybdenum profile, between 1.4 and 1.0 wt.\% in the first $10 \mu \mathrm{m}$ as observed in the EDX analysis presented in Figure 6. According to micrograph and the microhardness profile (Figure 5), this layer is composed predominantly of bainite. Despite this, some regions confirms the presence of martensite-austenite islands ${ }^{31}$ (indicated by circles in the Figure 4 (b)) previously demonstrated by XRD and reported by ${ }^{32}$ in an Astaloy Mo $+0.6 \% \mathrm{C}$ alloy.

Figure 4 (c) shows the SEM micrograph of the Ni2.5 sample. The enriched layer is not clear, but it was possible to observe the presence of two regions. The first region (surface region), present a thickness of $3.65 \pm 0.71 \mu \mathrm{m}$ and according to the chemical analysis (Figure 6), has a higher nickel content (between 17.8 and 9.9 wt.\%). In this region, the surface microhardness measurements showed a value of $441.9 \mathrm{HV} \pm 72.0 \mathrm{HV}$, that is in accordance with the taenite microhardness reported in ${ }^{28,29,30}$. Therefore, it is considered that this region is formed by the taenite phase. Below the taenite phase is the second region, this region is poorer in nickel (between $0.8-8.0 \mathrm{wt} . \%$ ) and has a lower microhardness ( 200 $-250 \mathrm{HV}$ ), as shown in the microhardness profile (Figure 5).
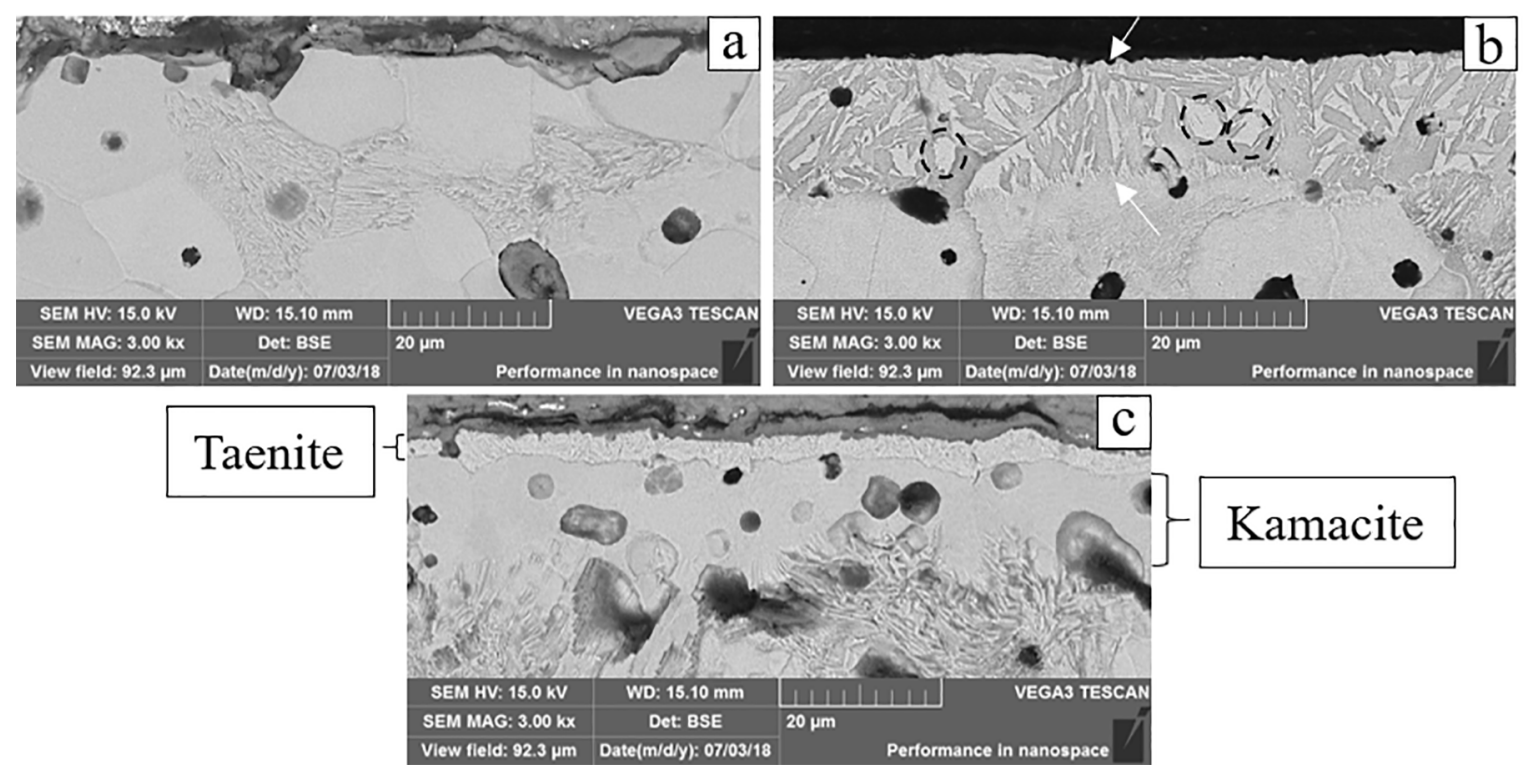

Figure 4. SEM imagens of cross section samples after chemical etching with Nital 2\%: (a) the presents phases in S1 sample was ferrite, pearlite and graphite, (b) for the Mo2 sample was also observed bainite and fractions of martensite-austenite islands, and, (c) the Ni2.5 sample presented the taenite and kamacite phases, in addition to ferrite, pearlite and graphite. 


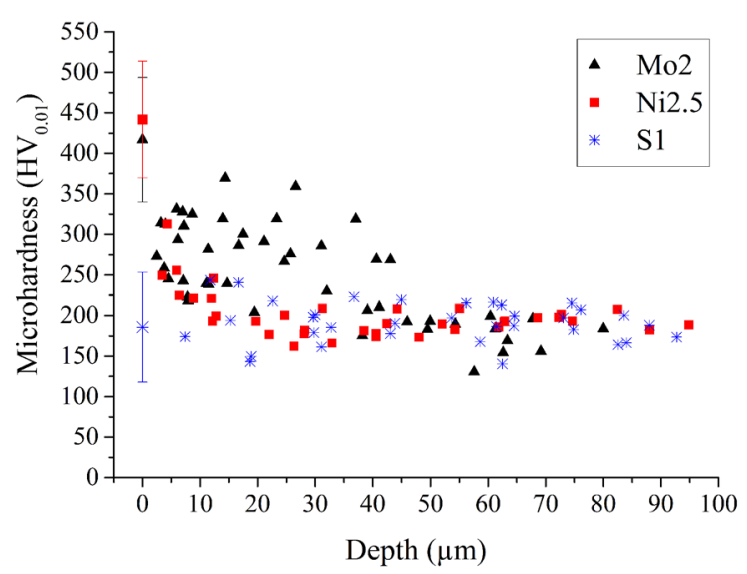

Figure 5. Microhardness profiles of the cross-section of the specimens. The surface microhardness values of the samples Mo2 and Ni2.5 were very similar, $416.8 \pm 76.9$ and $441.9 \mathrm{HV} \pm 72.0$ $\mathrm{HV}$, respectively. The error bars means the standard deviation of microhardness.

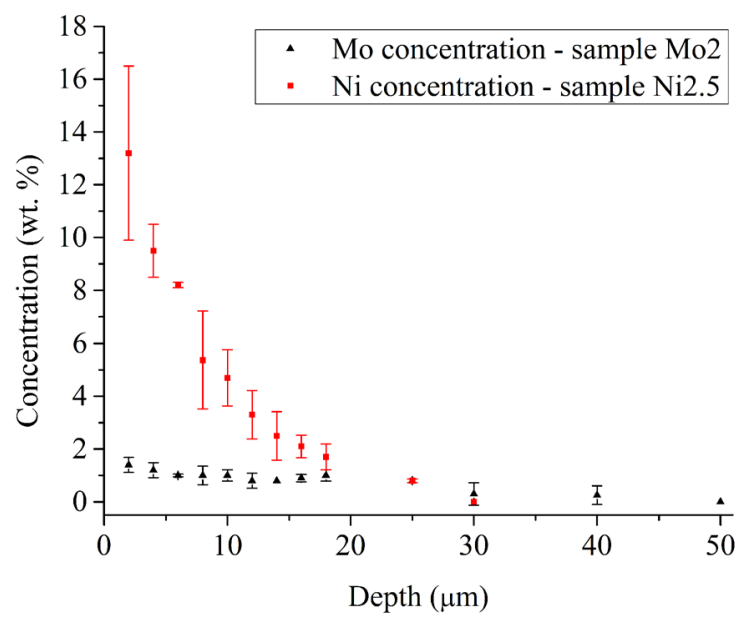

Figure 6. Chemical composition profiles, of the cross-section, obtained by EDX. For the Mo2 sample the profile remained practically constant in the first $10 \mu \mathrm{m}$. The error bars means the standard deviation of the chemical composition.

This result is indicative that the area below the taenite phase can be considered composed by kamacite phase.

The effect of enrichment treatments (Mo or Ni) were evaluated in relation to the tribological behaviour and to confirm whether the self-lubricating characteristic of the material was maintained after the plasma enrichment treatments. Figure 7 shows the wear rates of samples S1, Mo2, Ni2.5 and the respective counter-bodies. The Mo2 sample had the lowest wear rate. The wear rate value determined was 11.37 $\times 10^{-6} \mathrm{~mm}^{3} \mathrm{~N}^{-1} \mathrm{~m}^{-1}$, in opposite the wear rate of the reference composite ( $\mathrm{S} 1 \mathrm{sample}$ ) was $17.35 \times 10^{-6} \mathrm{~mm}^{3} \mathrm{~N}^{-1} \mathrm{~m}^{-1}$. This correspond to a $34.5 \%$ reduction. The Ni2.5 sample had a wear rate of $14.32 \times 10^{-6} \mathrm{~mm}^{3} \mathrm{~N}^{-1} \mathrm{~m}^{-1} \pm 3.62 \times 10^{-6} \mathrm{~mm}^{3} \mathrm{~N}^{-1}$ $\mathrm{m}^{-1}$ that is statistically equal to that of the sintered sample (S1) of $17.35 \times 10^{-6} \mathrm{~mm}^{3} \mathrm{~N}^{-1} \mathrm{~m}^{-1} \pm 1.85 \times 10^{-6} \mathrm{~mm}^{3} \mathrm{~N}^{-1} \mathrm{~m}^{-1}$. This indicates that $\mathrm{Ni}$ enrichment did not improve the wear rate of the samples. Figure 8 presents the effect of the enrichment treatments on the friction coefficient (lubricious regime) and the scuffing resistance. The Mo2 sample presented an increase around of $250 \%$ on scuffing resistance in relation to $\mathrm{S} 1$ and Ni2.5 samples. These results, were attributed to the increased mechanical strength of the matrix due to the molybdenum enrichment, that changed the metallurgical microstructure from ferrite/perlite to bainite/martensite. This increase in mechanical strength was corroborated by microhardness analyses that showed a hardening depth of $45 \mu \mathrm{m}$ to Mo2 sample.

Although having a surface microhardness similar to the Mo2 sample, the Ni2.5 sample showed similar scuffing resistance $(459,95 \mathrm{Nm})$ and wear rate $\left(14,32 \times 10^{-6} \mathrm{~mm}^{3} \mathrm{~N}^{-1} \mathrm{~m}^{-1}\right)$ as the sample without enrichment $\left(463,04 \mathrm{Nm}\right.$ and $17,35 \times 10^{-6}$ $\left.\mathrm{mm}^{3} \mathrm{~N}^{-1} \mathrm{~m}^{-1}\right)(\mathrm{S} 1$ sample). This can be explained by the lower hardness of the phase formed just below the surface (kamacite), which has a lower mechanical strength. The wear rate of the counter-bodies was higher for the samples Mo2 and Ni2.5, this behavior is due to the higher values of surface microhardness of these samples in relation to the reference sample.

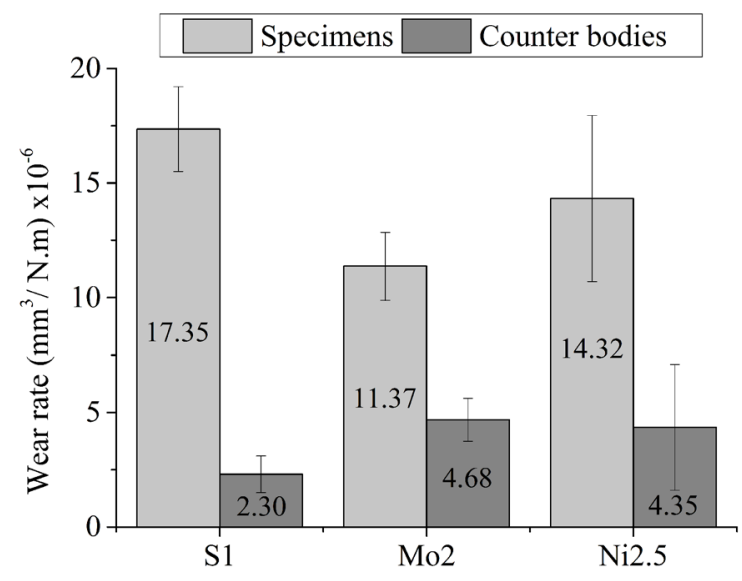

Figure 7. Wear rates for the specimens after reciprocating sliding for $1 \mathrm{~h}$. The Mo425 sample presented the best performance. The error bars means the standard deviation of the wear rates.

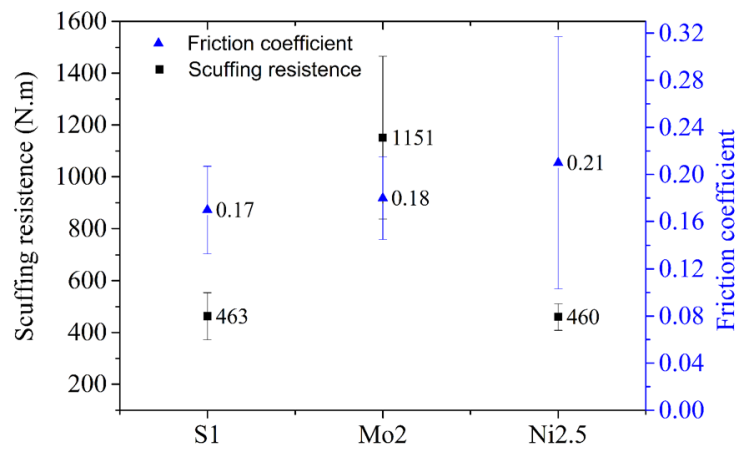

Figure 8. Friction coefficient and scuffing resistance of the samples. The enrichment with molybdenum maintained the coefficient of friction value and increased the scuffing resistence in relation to sample S1. The error bars means the standard deviation of the mean. 
The $\mathrm{S} 1$ and $\mathrm{Mo} 2$ samples presented similar COF values $(0.17 \times 0.18)$ indicating that the surface enrichment with molybdenum did not interfere with the lubricity effect. The Ni2.5 sample showed a COF that exceeded the lubricity limit (0.21) and a high standard deviation (Figure 8). However, a statistical analysis of the COF values showed that there was no significant difference between the COF values in the three conditions studied.

\section{Conclusions}

This study evaluated the influence of surface enrichment, with molybdenum or nickel, on tribological properties of selflubricating composites $(\mathrm{Fe}+0.6 \mathrm{C}+3 \mathrm{SiC})$. The solid lubricant used here were graphite nodules produced by the dissociation of SiC. The following conclusions can be established:

a) The surface enrichment treatments does not significantly cover the lubricant stocks.

b) The Mo2 sample presents the best tribological results, with an increase of $250 \%$ of the scuffing resistance, and reduction of $34.5 \%$ of the wear rate in relation to the sintered sample (S1).

The obtaining of solid lubricant stocks without significant coverage by the alloying elements, allows advances in the area of self-lubricating composites. This study showed the possibility of producing self-lubricating composites with improved tribological properties, without the conventional use of alloying elements in the form of dispersed powders in the matrix. This allows cost reduction in the production of these components, and avoids potential segregation problems during powder mixing. In addition, the surface enrichment can be realized several times with the same cathode being an environmentally friendly process.

\section{Acknowledgements}

The authors acknowledge the Brazilian founding agencies CNPq and UNIEDU Postgraduate program, as well as Embraco for their financial support. The research was supported by LABMAT - UFSC, LCM - UFSC and Materials Laboratory - IFSC.

\section{References}

1. Mello JDB, Binder C, Hammes G, Binder R, Klein AN. Tribological behaviour of sintered iron based self-lubricating composites. Friction. 2017;5(3):285-307.

2. Thümmler F, Oberacker R. An introduction to powder metallurgy. London: The Institute Of Materials; 1993.

3. Teisanu C, Gheorghe S. Development of new PM iron-based materials for self-lubricating bearings. Advances in Tribology. $2011 ; 248037$.

4. Bralla JC. Handbook of product design for manufacturing: a practical guide to low cost production. New York: McGraw-Hill; 1986.
5. Kalpakjian S, Schmid SR. Manufacturing engineering and technology. $7^{\text {th }}$ ed. Singapore: Pearson; 2014.

6. Xu J, Jiahe A, Xie X, Xu Z. Multi-element Ni-Cr-Mo-Cu surface alloyed layer on steel using a double glow plasma process. Surface and Coatings Technology. 2003;168(2-3):142-147.

7. Klein AN, Cardoso RP, Pavanati HC, Binder C, Maliska AM, Hammes G, et al. DC plasma technology applied to powder metallurgy: an overview. Plasma Science and Technology. 2013;15(1):70-81

8. Bendo T, Pavanati HC, Klein AN, Martinelli AE, Maliska AM. Plasma nitriding of surface Mo-enriched sintered iron. ISRN Materials Science. 2011;1-8.

9. Pavanati HC, Lourenço JM, Maliska AM, Klein AN, Muzart JLR. Ferrite stabilization induced by molybdenum enrichment in the surface of unalloyed iron sintered in an abnormal glow discharge. Applied Surface Science. 2007;253(23):9105-9111.

10. Cong W, Yao Z, Zhu X. Sliding wear of low carbon steel modified by double-glow plasma surface alloying with nickel and chromium at various temperatures. Wear. 2010;268(5-6):790-796.

11. Xu J, Mao X, Xie Z, Munroe P. Connecting structural, mechanical and tribological characteristics of $\mathrm{Al}$ alloyed nanocrystalline molybdenum silicide coatings. Journal of Physics D: Applied Physics. 2013;46(6):065304.

12. Xiushui Y, Wenping L, Qiang M, Yi X, Beilei R, Kai G. Tribological behavior of plasma Mo-alloyed layer on tc11 alloy under different loads. Rare Metal Materials and Engineering. 2015;44(3):557-562.

13. Lin CM, Kai WY, Su CY, Tsai CN, Chen YC. Microstructure and mechanical properties of Ti-6Al-4V alloy diffused with molybdenum and nickel by double glow plasma surface alloying technique. Journal of Alloys and Compounds. 2017;717:197-204

14. Damin KVS, Lucena AC, Bendo T, Binder C, Klein AN. Selflubricating composite with surface Mo or Ni-enriched produced by granulated or in situ generated lubricants. In: XVII Brazilian MRS Meeting; 2018 sep 16-20; Natal, Rio Grande do Norte, Brasil. Natal (RN): MRS; 2018. p. 264.

15. Binder R, Klein AN, Binder C, Ristow Junior W, inventor; Whirlpool SA, LupaTech SA, assignee. Composition of particulate materials for forming self-lubricating products in sintered steels, product in self-lubricating sintered steel and process for obtaining self-lubricating products in sintered steel. US patent 20110286873A1. 2009 Dec 09.

16. Binder C, Hammes G, Schroeder R, Klein AN, Mello JDB, Binder R, et al. 'Fine tuned' steels point the way to a focused future. Metal Powder Report. 2010;65(4):29-37.

17. Binder C. Desenvolvimento de novos tipos de aços sinterizados autolubrificantes a seco com elevada resistência mecânica aliada a baixo coeficiente de atrito via moldagem de pós por injeção [thesis]. Florianópolis (SC): Federal University of Santa Catarina; 2009.

18. Klein AN, Muzart JLR, Souza AR, Fredel MC, Wendhausen PAP, Rubens MN, inventors; LupaTech SA, assignee. Process for removal of binders from parts produced by powder injection molding. US patent 6579493B1. 2003 Jun 17. 
19. Machado R, Muzart JLR, Klein AN, Ristow W, Fredel MC, Wendhausen PAP, et al, inventors; LupaTech SA, assignee. Industrial plasma reactor for plasma assisted thermal debinding of powder injection molded parts. US patent 7718919B2. 2004 Aug 06.

20. Mello JDB, Binder C, Hammes G, Klein AN. Effect of the metallic matrix on the sliding wear of plasma assisted debinded and sintered MIM self-lubricating steel. Wear. 2013;301(12):648-655.

21. Metal Powder Industry Federation (MPIF). Standard $51-$ Determination of microindentation hardness of power metallurgy materials. Sweden: MPIF; 2010. p. 4.

22. Metal Powder Industry Federation (MPIF). Standard $52-$ Determination of effective case depth of ferrous powder metallurgy products. Sweden: MPIF; 2005. p. 2.

23. Mello JDB, Binder R. A methodology to determine surface durability in multifunctional coatings applied to soft substrates. Tribology International. 2006;39(8):769-773.

24. Totten GE. Steel heat treatment: metallurgy and technologies. $2^{\text {nd }}$ ed. Portland: CRC Press Book; 2006.
25. Brooks CR. Principles of the heat treatment of plain carbon and low alloy steels. $2^{\text {nd }}$ ed. Russell Township: ASM International; 1999.

26. Campbell FC. Elements of metallurgy and engineering alloys. Russell Township: ASM International; 2008.

27. Yang CW, Williams DB, Goldstein JI. A revision of the Fe-Ni phase diagram at low temperatures. Journal of Phase Equilibria. 1996;17(6):522-531.

28. Al-Bassam KS. The mineralogy and chemistry of the alta'ameem meteorite. Meteoritics. 1978;13(2):257-265.

29. Anthony JW, Bideaux RA, Bladh KW, Monte C, Nichols MC. Handbook of mineralogy. Chantilly: Mineralogical Society of America; 2017.

30. Dalton FK. Microhardness testing of iron meteorites. Journal of the Royal Astronomical Society of Canada. 1950;44:185-194.

31. Navarro-López A, Hidalgo J, Sietsma J, Santofimia MJ. Characterization of bainitic/martensitic structures formed in isothermal treatments below the $\mathrm{M}_{\mathrm{s}}$ temperature. Materials Characterization. 2017;128:248-256.

32. Höganäs AB. Handbook 3 - design and mechanical properties. Sweden: Höganäs AB; 2015. 